\title{
Commentary
}

\section{Commentary on the installation of Professor WH Donovan as President of ISCOS}

Spinal Cord (2005) 43, 133. doi:10.1038/sj.sc.3101714; Published online 25 January 2005

Dr William H Donovan was installed as President of the International Spinal Cord Society (ISCOS) at the 43rd Meeting in Athens, Greece on 29 September, 2004. He is currently the Professor and Chairman of the Department of Physical Medicine and Rehabilitation (PMR) at the University of Texas Health Science Center Houston, TX, USA and holds a joint appointment as Adjunct Professor in the Department of PMR at the Baylor College of Medicine, Houston, TX, USA. He enjoys the reputation as one of the foremost figures in Spinal Cord Injury (SCI) care in the USA in his capacity as Medical Director and Director of the SCI Center of The Institute of Rehabilitation Research (TIRR) in Houston.

Dr Donovan's contributions to the field of SCI include over 100 published papers, book chapters and monographs with major emphasis on neurological classification, treatment of pain and urinary tract infections. He is an accomplished physician and teacher, who has lectured throughout Europe, Asia, Australia, North, Central and South America. He is also admired and appreciated by his residents as a bedside teacher and held in high esteem by his peers. Several of his unique achievements include an SCI fellowship for 3 years
(1977-1980) under the mentorship of the late Sir George Bedbrook in Perth, Australia and the Elkins Scholarship Award for attaining the highest mark in the Specialty Board Examination in 1975. He has served as President of the American Spinal Injury Association (ASIA) 1987-1989 and will receive the highest recognition, the ASIA Lifetime Achievement Award at their annual meeting in May 2005.

In addition to his long service to ISCOS as a member for 24 years, he has served on Council since 1986 and Vice-President for North America for the past 4 years. Prior to his installation as President in Athens, he received the highest recognition of the Society with the award of the Silver Medal. We are confident that the organization will grow and flourish under his expert guidance and welcome him as our leader for the next 2 years.

John F Ditunno Jr

Thomas Jefferson University, 132 South 10th Street, Suite 375 Main Building, Philadelphia, PA 19107, USA E-mail: John.Ditunno@mail.tju.edu 